I Universidade Federal de São Carlos (Ufscar),

Departamento de Ciências Sociais, São Carlos, SP, Brasil

villela@ufscar.br

https://orcid.org/o0oo-00oI-5240-4654

Jorge Mattar Villela'

\title{
MEMÓRIA E THANASIMOLOGIA POLÍTICA NO SERTÃO DE PERNAMBUCO
}

\section{INTRODUÇÃO'}

Este artigo fala dos mortos nas vidas dos vivos e dos vivos nas vidas dos mortos. Ele deriva de uma pesquisa posicionada, desde I999, no sertão de Pernambuco, especificamente no município de Floresta, localizado na mesorregião do São Francisco e na microrregião de Itaparica, a cerca de 500km de Recife. Ali, essa relação entre vivos e mortos é regulada pela memória, pela vingança e pela política, levando-se em conta a indissociação desses aspectos aos da religião, do território e, evidentemente, do sangue, da família e, enfim, do parentesco.

O objetivo deste artigo é o de mostrar a necessidade, tão sincera quanto estratégica, de posicionamento no mundo por meio da constituição e manutenção da memória dos mortos para a fabricação e exaltação de uma família, ${ }^{2}$ termo cujos sentidos são cambiantes e polissêmicos. Esse argumento é sustentado pelo núcleo etnográfico do texto: o personagem de Totonho do Marmeleiro, cuja morte ocorreu, segundo os relatos dominantes atualmente, no meado do século XIX, em meio à caatinga, a I $6 \mathrm{~km}$ da fazenda Ema; esta, por sua vez, distante $42 \mathrm{~km}$ da sede municipal de Floresta. Pretendo mostrar que a celebração recém-criada em sua homenagem funciona como uma mnemotecnia capaz de celebrar a memória de um morto que, por sua vez, torna-se o meio de enfatizar a unidade, a força e as dimensões de uma família há muitas décadas posicionada longe da administração de Floresta, mas também de fazer comunidade e de reunir pessoas em torno de um ritual religioso. Essa família é co- 
nhecida como o 'o povo da Ema', em certos casos, 'os Gregório ou os 'Ferraz da Ema'. Vale adiantar, portanto, que a exaltação de um indivíduo é o meio pelo qual uma família se faz e se dá a ver publicamente. Por outras palavras, família no sertão de Pernambuco se faz por individualização de um ancestral, quer dizer, de um parente morto.

Vale desde já adiantar que este artigo se insere na produção bibliográfica e nos debates concernentes à antropologia da política, da família e dos mortos e não nos da antropologia da morte e do ritual. Ele fala de mortos e, mais particularmente, da relevância dos mortos na vida dos vivos e do que os vivos fazem os mortos fazerem por eles.

A proposta deste artigo insere-se precisamente nesta discussão, a saber, a que pretende descrever analiticamente os modos pelos quais os vivos mobilizam os mortos em suas próprias vidas conferindo-lhes uma existência de que não disporiam não fossem certas incitações dos vivos uns em relação aos outros em suas vidas cotidianas.

Inicio a análise apresentando as circunstâncias locais nas relações entre vivos e mortos no que toca às relações familiares e às da política, e sigo pela análise da memória genealógica, fundamental para compreender essas relações. Posteriormente, esse aspecto será complementado com a constituição de uma história que opera por meio da genealogia. Finalizo o texto avançando uma reflexão acerca da temática bastante geral entre política, família e Estados nacionais inspirada pela construção de personagens que formam coletividades e circunscrevem pertenças.

\section{OS MORTOS E A POLÍTICA}

Os mortos, assim como as famílias, e os mortos por conta das famílias têm sido formadores e conformadores das práticas cotidianas e extraordinárias das democracias modernas e contemporâneas. Os mortos criam lugares, montam genealogias, estabelecem ligações matrimoniais, formam partidos. Afinal, é com os mortos que se fizeram, e também se desfizeram, história e consciência nacionais (Detienne, 2010). Em sua memória celebram-se as nações e se estabilizam as fronteiras. Ela reforça os governos dos povos e os incita contra seus inimigos.

Assim, grandiosas ou acanhadas e a despeito do seu alcance para fora dos seus objetivos táticos e imediatos, a história política dos países ocidentais não costumou abrir mão dos usos que os vivos fazem dos seus mortos, sejam eles indivíduos ou indivíduos coletivos (o espírito de um povo), religiosos ou laicos (o Mavzolei Lenina, o solo sagrado de Jerusalém). Pelos mortos, construíam-se as individualidades dos vivos em função dos sangues que, misturados pelo casamento, deram origem à sua força, bravura e lealdade; mas também às sucessões monárquicas ou senhoriais. Os mortos, portanto, são responsáveis pela individuação dos vivos desde que estes últimos sejam capazes de manter a individuação dos seus mortos. 
O modo de individuação dos mortos levado a efeito pelos vivos diz respeito às suas biografias. A seleção do que fizeram e, não menos importante, do que disseram em momentos decisivos de suas existências para a gravação de suas memórias. Esse é o cerne do caráter do herói no pensamento europeu: ele fala e age, e, por suas palavras e ações, é eficaz. Veremos, e nisso reside tanto para o sertão quanto para demais circunstâncias históricas, a singularidade do tema de Totonho do Marmeleiro, já que sua individuação efetuada por alguns de seus descendentes dispensa o relato ou a refacção de sua vida, assim como atos de palavras que a tenham marcado. Antonio da Costa Araújo, o Totonho do Marmeleiro aparenta-se às figuras do ancestral fundador, do mártir e do herói, mas delas distingue-se fortemente. Nominado, a impossibilidade de conhecer sua vida também se distingue da impossibilidade equivalente do herói anônimo ou desconhecido.

A modelização sertaneja das citações individua e individualiza um ancestral. Em muitos casos, essas palavras inscritas na memória e reproduzidas nas bocas de seus descendentes foram proferidas quando a sua coragem foi requisitada, quando suas vidas se puseram em risco pela ousadia de sua oratória. Os distingue, portanto, dos parradores, para usar o termo sertanejo, quer dizer, os que falam no vazio dos acontecimentos, sem fundamento factual, em que nada nem ninguém é desafiado, em que nenhuma coragem é exigida, em que a palavra é sem ato e não comporta riscos. 'A partir de hoje eu sou político'; 'não vou dar munição a bandido'; 'Se o capitão [Lampião] for lá [lugar em que viviam parentes distantes do sujeito de enunciação], saiba que eu vou dar retaguarda a eles'. A reiteração de frases como essas fez de alguém o que ele ou ela é, mesmo morto ou morta; faz de todas as pessoas que se posicionaram ou foram posicionadas, e assim são reconhecidas pelos demais como seus descendentes, o que eles são ou o que poderão ser, dizer, fazer ou ambicionar.

Esses momentos excepcionais, escritos em textos de duas, três páginas, é o que se chama de biografia no sertão. O grande modelo desse esquema talvez seja Wilson (1974, I978), natural de um município vizinho, dedicado à história municipal desde 1972. Sua obra realiza essa tarefa ao selecionar "grandes sertanejos", cujos feitos da vida das armas deram ao sertão e suas famílias o aspecto que tinham na época do autor. É o discurso triunfalista de um lugar a respeito de si mesmo. Seu principal argumento são as vidas desses personagens. Em muitos dos inúmeros livros de genealogia, alguns dos mais destacados personagens de cada família recebem a dignidade de ter um breve resumo de suas vidas e de sua personalidade, relevantes na composição das famílias, mas não necessariamente na fundação do sobrenome. Essas pessoas muitas vezes são reconhecidas como um tronco. Em meio às metáforas vegetais dos ramos e dos troncos circula uma espécie de seiva que é o sangue, um veículo caracterizador do que uma pessoa é, justificativa dos seus atos e gestos e não apenas da sua aparência, visto que esta não se dissocia daqueles. 
É apenas nesse sentido que o modo como se viveu implica o modo como se deu a morte de um tronco, assim como costuma ocorrer nas biografias dos heróis nominados, mas não dos desconhecidos. Destes últimos recolhem-se apenas o modo como a morte lhe foi dada, sem recurso possível à maneira como conduziram suas vidas. Se o nome não é coextensivo à condição de herói, o mesmo não pode ser dito dos seus atos, sequer os de palavra. As definições do verbete "herói" nos dicionários OED, Larrouse e Caldas Aulete, implicam a existência de uma biografia. Os textos mais clássicos, como o de Thomas Carlyle também insistem no tema da biografia associado ao que fizeram ou do que foram capazes, a partir desta posição de fazer ou de dizer (Jones, 2007). A extensa literatura acerca do tema insiste nos aspectos coletivos e voluntários da morte heroica (Rassool, 2004; Albert, 2007; Marschall, 2008). Esses são temas que afastam a posição de Totonho do Marmeleiro da temática do herói, ainda que esteja aparentada com ela, levando-se em conta o empréstimo das qualidades morais do vaqueiro à sua vida desconhecida (Cubitt \& Warren, 2000).

O resgate das biografias dos que caíram anônimos nas batalhas ou em massacres é uma das lutas empreendidas pela mnemopolítica descrita em trabalhos como os de Verdery (I999), Sanjurjo (20I3), Petrovic-Steager (20I I) e King (20I0). As circunstâncias de individualização e politização da morte do protagonista deste artigo parecem-me diferir na organização e nas ênfases da biografia e da thanatografia, o relato da vida e o relato da morte. Pois o que chamo de thanasimologia política, o dizer os mortos, baseia-se na vida, mesmo quando a morte é o ponto nodal do relato e o mote da individualização de um morto. O caso de Totonho impede a realização de uma biografia, ainda que insista na thanasimologia. ${ }^{3}$ Daí o apelo à condição mais geral e despersonalizada do vaqueiro como meio de individualização de um personagem nomeado, mas desconhecido.

É, pois, no processo de individualização sob a forma de um tronco, cujo sangue sempre mistura outros sangues, que uma raça ou família ganha realidade e substância. A individualização de um ancestral, por meio de sua celebração e celebrização, é fundamental para o agrupamento de pessoas cujas linhas de parentesco atam-se em algum, mas em geral em vários momentos do passado e em vários pontos do emaranhado genealógico. Até recentemente eu só havia verificado essa atitude em relação ao parentesco nos casos em que os troncos já estavam feitos e restava aos vivos apenas esforçar-se para inserir-se sob uma descendência construída de direito, mas nem sempre de fato (Villela, 2015).

A novidade de alguns anos para cá foi a construção de troncos no presente. A primeira ocasião pareceu-me uma emulação acelerada dos processos já entronizados na região. Uma família, proveniente da zona rural de um antigo distrito de Floresta, cuja urbanização, bem como a educação formal de seus jovens, fornecia a ela os meios de criar o seu tronco e de se expor publicamente como uma família digna de reconhecimento público, quer dizer, numerosa e unida. A ela restava comprovar a sua antiguidade, o que se fez por meio da 
pesquisa genealógica. A respeito daquele processo, nota-se o esforço conjugarse com as possibilidades políticas de um dos membros dessa família que se candidatara a uma vaga na câmara municipal (Villela, 20I5). Sobretudo porque o êxito dessa candidatura também contribuiu para a confirmação do próprio esforço de fazer família. Afinal, assim como a família faz política, a política também faz família (Villela, 2009).

As circunstâncias e a motivação do exemplo a que este artigo é dedicado, no entanto, diferem vigorosamente desse caso por três motivos: pela preexistência da família em questão como ramificação da família Ferraz vastamente constatada pela pesquisa genealógica e, consequentemente, pela fixação prévia desse ramo sob a biografia de um tronco já determinado há várias décadas; pela escolha de um novo tronco desvinculado da vida político-partidária e eleitoral; e pelo fato de a base discursiva da construção do tronco não ser a sua biografia, mas a sua thanatografia, não a sua vida, mas a sua morte.

\section{FLORESTA, SEUS VIVOS E SEUS MORTOS}

Segundo a história municipal, amplamente chancelada pela bibliografia disponível, cujas publicações são estimuladas por várias administrações municipais, em I9I3 a política florestana foi dividida em dois partidos-família (os Ferraz e os Novaes) que disputaram as eleições municipais e partilharam o colégio eleitoral acoplando-se às candidaturas e às coligações adventícias da política estadual e nacional e às suas transformações históricas. Naquele ano, segundo os relatos constantes em alguns livros de genealogia, política e história, alguns personagens passam a dirigir a grande divisão efetuada entre políticos e não políticos nos pleitos e na vida partidária em Floresta ('a partir de hoje sou político', um exemplo forte de ato de palavra individualizante e formador de tronco). Baseiam-se nessa cisão não apenas os grandes sobrenomes capazes doravante de concorrer nos destinos da administração pública, mas as linhagens e seus descendentes habilitados a disputar cargos eletivos, sobretudo o do Executivo municipal.

Esse é o quadro geral das relações entre família e política necessário para a singularização das circunstâncias de transformação de Antonio da Costa Araújo em ancestral de destaque (tronco). Pesquisa genealógica e história municipal se enlaçam formando uma dupla exigência: a de que os mortos sejam ditos e lembrados forjando e temperando a envolvência de certos descendentes em sua linhagem e de que esses, por sua vez, habilitados a concorrer a cargos eletivos, devolvam aos mortos a possibilidade de entronização, num ciclo de mútua alimentação; a de esquecimento de alguns dos descendentes dos mesmos mortos e de outros mortos, de modo a selecionar, por meio da genealogia, alguns dos pretendentes a cargos políticos. A fabricação da família, por meio da celebrização dos e das ancestrais, faz-se, assim, uma tripla prática de inclusão/exclusão, pelo sangue, pelo partido e pela facção. 
Mas a genealogia florestana exige outra forma de fabricação de família que se pretende liberada da thanasimologia política, do modo político de dizer os mortos. A segunda parte deste texto será a descrição de um processo de fabricação de família, o mais espetacular (mas não o único) que testemunhei em I7 anos de pesquisa de campo na região. Ela se expressa na, mas não se reduz à, celebração de uma missa em memória de um vaqueiro morto há mais de 150 anos.

\section{A HOMENAGEM A TOTONHO DO MARMELEIRO}

Embora imiscuída nas vésperas das eleições municipais, um dos traços distintivos dessa celebração em memória de um ancestral era a insistência dos/as organizadores/as em manter a política eleitoral e partidária afastada do evento. 'Sem chapa, sem campanha, pelo amor de Deus', insistia uma delas. ${ }^{4}$ E essa era apenas uma das peculiaridades desse evento.

Essa missa não implicava a invenção de uma família, lembremos, posto que os Ferraz da Ema, territorialmente referidos à Ribeira da Ema, localizada no segundo distrito de Floresta, são reconhecidos como uma 'família antiga' pelos livros de genealogia da família Ferraz da cidade de Floresta. Seu parentesco com os Ferraz de Floresta é comprovado pela adesão de parte do povo da Ema à política dos Ferraz, mas também por um ancestral comum, o sogro de Totonho do Marmeleiro, falecido em I833. Tanto nos processos eleitorais quanto na administração municipal esses ramos costumam acompanhar ${ }^{5}$ essa política, quer dizer, o partido dos Ferraz. Não obstante, a sua própria inserção como família, como descendentes de um tronco, de um fundador, que os habilite a concorrer a cargos eletivos, ganha ambiguidade em virtude da aliança do homem até recentemente reconhecido como o mais importante dentre os seus, o major João Gregório (falecido em I932), com uma família-política cujo protagonismo na administração pública foi substituído pela dos Novaes a partir de I913: os Carvalho, muito numerosos até hoje, de quem os Novaes herdaram o antagonismo político com os Ferraz.

A relevância do major mede-se pelo número de descendentes batizados com seu nome (usado como segundo nome ou como primeiro), até o presente, mesmo quando se trata de moças, e pelo fato de a Ribeira, o parentesco e a patronimização de seu prenome identificarem-se ao território, à Ribeira da Ema. João Gregório Ferraz Nogueira, major da Guarda Nacional, subprefeito de Floresta, tinha relações com algumas das mais importantes figuras da política vétero-republicana como, por exemplo, Francisco da Rosa e Silva. ${ }^{6}$ Sua biografia é vastamente conhecida, assim como seu senso de justiça, seu espírito pacificador e seus conhecimentos de medicina. Características retomadas pelos seus descendentes para caracterizarem-se e reconhecerem-se a si mesmos como Ferraz da Ema, como os Gregórios. A ambiguidade da posição política do povo da Ema deve-se ao fato de alguns dos descendentes imediatos do major, 
assim como as casas que lhe correspondem, terem acompanhado a 'política dos Novaes'. Os que se mantiveram aliados aos Ferraz de Floresta ao longo dos anos pagaram o seu preço por essa divisão.

De certo modo, a celebração de Totonho como tronco em substituição ao major João Gregório pode funcionar como correção dessa equivocidade política. A missa, portanto, fazia recuar em uma geração o posicionamento do tronco. Um personagem, sogro de João Gregório, cuja existência é descrita por vias ambíguas, cuja biografia é desconhecida, cujos descendentes estavam quase dispersos e, enfim, cujo local de nascimento nem sequer era a Ema ou o segundo distrito ou o município de Floresta. Um defunto, vale lembrar, do qual não se tinham notícias - nem do corpo, nem do sepultamento, nem dos restos, nem do kolossós. Suas circunstâncias distinguem-se das dos mortos estudados por uma antropologia que se atém aos corpos como possibilidades mnemônicas de atribuição de sentido, significado e fixação de identidades (Sanjurjo, 20I3; Petrovic-Staeger, 20I I; Verdery, I999; Hayden, I996) que exigem mausoléus, exumação dos restos mortais, recomposição química da identidade do DNA. Veremos que a pesquisa dos traços da vida de Totonho são as menos exigentes e sua aceitação, a mais generosa.

Antonio da Costa Araújo, o Totonho do Marmeleiro, homenageado anualmente em uma missa campal em plena caatinga, consta na mais famosa genealogia da família Ferraz, publicada em meados dos I990. Filho de Triunfo, cuja sede municipal é atualmente separada da fazenda Ema por quase rookm, assim como diversas pessoas de lá, veio casar-se ali, onde também fixou residência, com uma das filhas do proprietário da antiga Fazenda Algodões, da qual a Ema é um desmembramento por herança. Vaqueiro de profissão (o que me parece enigmático, uma vez que era brejeiro7) teria morrido quando do retorno de uma comitiva, sozinho, no pé de um pereiro, na exclusiva companhia de seu cavalo e de seu cão fiel, que lhe guardou o corpo do ataque dos carcarás.

Não há confirmação e nem exigência de confirmação dessa história que se tornou conhecida pela boca, pelos esforços e pelos escritos inéditos de meu finado amigo Napoleão Ferraz Nogueira, seu Napole, neto do major, que a ouviu do vaqueiro Genésio de Nato: 'vaqueiro catingueiro como você eu só vi Totonho do Marmeleiro'. Foi o que teria dito a Genésio o seu avô, segundo o próprio Genésio no relato que fez a Napole que, então, concatenou essa história a seus conhecimentos genealógicos. Segundo um dos filhos de Napole, a descoberta se deu pelo seguinte diálogo:

Aí Genésio disse assim: vá lá no córrego de Totonho. Aí [Napole] disse assim: quem é esse Totonho? Aí Genésio de Nato disse que o pai dele contava que tinha esse vaqueiro que vinha e levou uma pancada, toda a história. Aí [Napole]: ô xente! Antonio da Costa Araújo [este último sendo o sobrenome de vários parentes próximos de Napole]? Aí ele foi pesquisar. Aí tinha inclusive um livro aí no cartório com a herança da Bahia. Umas terras que tinha lá inundadas. 
Foi assim que Gilson, o atual organizador da celebração, filho de Napole, guardou em sua memória o primeiro contato de seu pai com Totonho. Motivado pela curiosidade genealógica em torno da sua família, Napole chegou aos registros da herança e conseguiu obter, por meio de sua persistência e de suas pesquisas, a indenização paga pela Cia. Hidrelétrica do São Francisco (Chesf) aos proprietários de terras inundadas pela barragem de Paulo Afonso. E isso é o que se sabe dessa vida enigmática de Antonio da Costa Araújo, um nome, no entanto, já mencionado desde a infância de uma das irmãs mais velhas de Napole, ela também casada no Brejo. ${ }^{8}$

A partir daí, Napole concebeu uma homenagem ao homem esquecido nas caatingas, mas ancestral de uma enorme descendência. Ancestral, mas ainda não tronco, vale adiantar. Essa primeira homenagem foi uma missa à qual, segundo se diz, compareceram seis pessoas, o padre incluído. Ela foi, sem que se soubesse ou desejasse, o primeiro passo para a transformação de Totonho de ancestral em tronco. E essa não era uma missa do vaqueiro, ainda. Era apenas a marcação de um lugar, a entrada na memória familiar de um personagem até então perdido e esquecido.

\section{DUPLA CELEBRAÇÃO AOS MORTOS}

Foi outra morte, a de Napole, idealizador da celebração e, após a sua morte, também homenageado, o evento multiplicador da missa anual, maior a cada ano, e que tirou Antonio da Costa Araújo do esquecimento quase completo. A única marca deixada por ele era, até então, suspeito eu, cartorial: seu registro de nascimento, de casamento, os de nascimento de seus filhos e os títulos de propriedade de terras. A morte de Napole exigiu de seu filho, Gilson, uma homenagem. Dizer outro morto, bem conhecido conquanto lateral mesmo em meio ao povo da Ema, ampliou a celebração, antes doméstica, para um evento público. Os esforços e os recursos passaram a ser angariados junto ao empregador de Gilson e a seus primos de outro município, descendentes de Totonho e de João Gregório. Sua prima Amélia Araújo, figura cada vez mais central na família e na organização dos eventos culturais no município, passou a atuar com mais vigor também como organizadora tanto do evento quanto do livro da genealogia de Totonho (Ferraz, Araújo \& Araújo, 20I5) em associação com outro primo, Magno Araújo, residente em Brasília, uma nova edição a cada ano atualizada pelas pesquisas genealógicas da e dos autores. A organização do evento e as edições do livro revelaram e levaram à missa bisnetos residentes em várias parte do estado, além dos residentes no sertão de Pernambuco, já conhecidos, os homenageados da edição de 20I6. Ademais, as pesquisas decorrentes do evento revelaram bisnetos e trinetos vivendo fora de Pernambuco e do Brasil. Afinal, sem genealogia, sem família e sem troncos não se constitui uma genealogia.

Aqui temos este aspecto, relativamente novo, da thanasimologia sertaneja: a celebração pública dos mortos não exclusiva às famílias políticas e 
como forma apenas secundária de sua legitimação política. Ela é feita por meio de efemérides, geralmente nucleadas pela liturgia católica, à qual já retornarei; são eventos periódicos que ocorrem em datas mais ou menos precisas. Sua celebração, vale reiterar, é uma das maneiras de congregar e manter reunidas, com capacidade de ostentação de si, famílias mais tradicionais.

Não custa insistir na ideia de que a própria existência de Antonio da Costa Araújo remete à sua morte. Foi a sua thanatografia e não a sua biografia que o tornou célebre, que o fez aparecer no mundo. O destaque do avô de Genésio era a sua habilidade na caatinga. Mas o que a ela se transmitiu da informação do pai de Genésio não foi o mesmo de Genésio a Napole, que viria a descobrir-se descendente desse novo personagem familiar. O que Napole fez perseverar não foi a sua habilidade. Foi essa forma de morrer sozinho. A solidão e o esquecimento atraíram o interesse e a piedade de Napole. No livro anual de sua genealogia, cuja última edição lista os 2.045 descendentes em nove gerações, não há traço de biografia, quer dizer, nem ações nem atos de palavra. Ali, como em outros escritos semelhantes, a noção de história é redutível à da descendência do biografado. No sertão de Pernambuco genealogia é história. Os textos, que ocupam sete páginas do total de I87, são depoimentos, recapitulações e elogios à celebração, e, enfim, um texto de Napole a respeito de Totonho que começa pela homenagem "a um vaqueiro que perdeu sua vida no cumprimento de seu dever", que "era natural de Triunfo", que casou com "Ana de Souza Ferraz" que "morava no sítio Marmeleiro". Meio de vida, local de nascimento, nome da esposa. Fala também da sua riqueza: era proprietário de 400 mil réis de terras no mesmo sítio e 100 mil réis em Casa Nova, na Bahia, e mais 50 mil no sítio Brejinho, em Triunfo. Fortuna incompatível com a angariável por um vaqueiro, portanto. Pelas pesquisas feitas nos testamentos, Napole sabia que Totonho era também boiadeiro e

possuía tanto dinheiro que espalhava nos couros para não criar zinabre [...] Nas festas juninas sua casa era bastante frequentada, vinha gente de longe para passear, tal como Dona Marina da Fazenda Modubin, que ficava próximo a Betânia. Esta senhora, os escravos a transportavam em uma liteira, espécie de andor. A mesma vinha toda adornada de ouro, até mesmo os dentes que possuía eram de ouro.

Em seguida, Napole descreve o episódio da morte de Totonho, o trecho mais longo do texto, visto que as informações sobre a sua vida esgotaram-se:

Até que certo dia partiu uma boiada. Totonho partiu na frente para pegar um boi nas caatingas, hoje fazenda Lucas, e combinaram para se encontrarem na fazenda Bonito. Com três dias, chegou o cavalo. O pessoal aflito foi a sua procura, encontrando Totonho morto [...] Ele tinha levado uma forte pancada em um pé de aroeira e veio a falecer. O seu cachorro de estimação estava vigiando o cadáver. Prosseguiram com o seu corpo até a lagoa de Martin Mendes, onde sepultaram, pois nessa época só existia cemitério em Floresta e Serra Talhada. 
Napole lembra, então, os I 3 filhos que o casal, bisavós do autor do texto, deixou e a existência de um açude, que supõe ser o primeiro da região, nas vizinhanças da casa em que morava essa família, signo das terras mais valorizadas. Finalmente, menciona enorme descendência, "espalhada por todo o Brasil", fazendo com que essa história "faça parte da História do Brasil". Por isso, essa "celebração se assemelha com a Primeira Missa [...] aquela grande cruz, aquelas árvores e aquele areal”.

Embora rara, essa situação não é exclusiva. Ela contém, portanto, alguma especificidade, curiosamente, nos dois sentidos da palavra: ela é singular e, no entanto, não é individual. Apela para o interesse renitente na genealogia por um lado e, por outro, indica linhas de demarcação do parentesco.

\section{MEMÓRIA E HISTÓRIA EM FLORESTA}

A primeira tendência faz a genealogia repousar nas bases do virtual integral da genealogia, o todo completo, conquanto indizível, anterior à declinação dos nomes e inextensivo do parentesco (Villela, 2004; Villela \& Marques, 2016). A segunda faz da história municipal e genealógica um recorte extensivo (o virtual que se atualiza) do estoque virtual do parentesco concernente às pessoas que importam aos conjuntos dos que fazem a sua história e, sobretudo, às linhagens em que se inscrevem os e as historiadores/as.

A história municipal e a genealógica em Floresta são feitas nas bases, digamos, da atividade da história tal como a caracteriza Weber: seus inventariantes interessam-se em certas categorias de acontecimentos, mas, sobretudo, em certas pessoas que se poderiam chamar, no vocabulário sertanejo, como também em Weber (I 968), de povos. Assim, o povo da Ema se interessa pela história do povo da Ema, assim como os genealogistas dos Ferraz de Floresta se interessam mais pelo seu povo. Esse modo de fazer história, por sua vez, envolve dois aspectos cruciais: o da verdade e o do território.

Em relação à verdade, as historiadoras e os historiadores florestanos seguem até certo ponto a antiga fórmula de Langlois e Segnobos (20I4), cuja edição original é de I897, segundo a qual é preciso enfrentar o passado como um paisagista limpa a realidade verificada de toda poeira e a restitui tal como ele a testemunha. A única coisa a omitir da totalidade da paisagem era o pintor-observador, pois residia nele toda a possibilidade de erro. As leitoras e os leitores florestanos e os historiadores entre si, no entanto, monitoram a presença do pintor. Porque, enfim, suspeita-se ali (bem mais do que na França fin de siècle) que toda história é territorial e, simultaneamente, genealógica e política. A verdade, assim, é constantemente assombrada pela tendência ao erro ocasionada pelo sangue, pela família e, correlativamente, pelo território (a casa, a ribeira, o lugar) do pintor. Ela se faz segundo as tentativas de fazer família, ancestralidade e, não menos importante, a si mesmo(a) por meio da celebração e celebrização de um ou mais troncos de uma descendência. As historiadoras e os historiadores florestanos criaram 
uma membrana em torno das grandes famílias, dos seus locais de nascimento, dos seus troncos, que as isolavam das demais e atraíam para si, ao mesmo tempo que afastavam das outras, o interesse e as possibilidades de ação política, assim como o interesse das e dos demais habitantes. Territorial, portanto, a verdade é alvo das críticas dos(as) leitores(as) nascidos(as) em outros territórios, que os(as) diferenciam e, em certos casos, alijam das cadeias discursivas do parentesco, ao passo que eles(as) se sabem incluídos(as) no estoque inextensivo (virtual) do sangue (afinal, ali 'é tudo braiado'; todo mundo é parente de todo mundo).

O processo de transformação de Totonho em tronco é um movimento capaz de romper essa membrana, de resto, aqui e acolá, quebrada por movimentos semelhantes, embora distintos na forma e na tática. Ao contrário das demais, baseadas na biografia, não custa insistir, foi sua morte a forjadora de seu caráter, o caráter tomado de empréstimo da figura ideal do vaqueiro, modo de vida que, inversamente, acarretou sua morte. Totonho, lembremos, segundo Napole, morreu no cumprimento do seu dever. No mesmo livro, após a foto de Napoleão sentado na calçada de sua casa, talhando suas esculturas de pedra-sabão, segue-se a toada escrita em homenagem ao falecido vaqueiro. O que lhe reservou a voz do poeta foi a sua profissão (ainda que sua riqueza o aproxime mais de um boiadeiro), o destemor, a lida com os animais, a firmeza; mas também sua vasta prole e o nome de sua esposa. Das seis estrofes, no entanto, três são reservadas à sua morte, a face mais conhecida e extraordinária de sua vida, roteiro da morte que traslada do esquecimento à glória uma vida quase desconhecida. Na impossibilidade de o fazer por sua vida individual, faz-se pela do futuro que plantou em sua prole, mas, sobretudo, pela sua atividade, a de vaqueiro. Não foi a vida de Totonho como vaqueiro que inspirou a sua homenagem. A expressão cerimonial da consolidação da sua existência só após a morte de Napole foi transformada numa missa de vaqueiro. Houve certa deriva da posição de um ancestral de uma família específica à condição de um personagem a quem se acopla a celebração de um ideal sertanejo, a figura do vaqueiro, uma imagem do próprio sertão, ao mesmo tempo em que se afasta dele a figura do boiadeiro rico.

Este último aspecto é fundamental para a compreensão da homenagem à memória desse homem. Ele confere singularidade ao modo como os Ferraz da Ema entendem-se e se mostram como família, cuja descendência de Antonio da Costa Araújo faz particularmente grande e unida e que se celebra ao mesmo tempo em que celebra o seu (novo) tronco. A imagem do vaqueiro, como foi recentemente mostrada por Pereira (20I7), dispõe da propriedade de eternizar o tempo. Ela consiste, portanto, num oximoro. O desfile da vaqueirama, uma parada que atraiu a atenção de todas as 500 pessoas - mesmo a dos candidatos às eleições municipais e dos(as) políticos(as) (incluídos um deputado federal e outro estadual), que aproveitaram o ajuntamento para ajustar os compromissos com os eleitores, mostrar-se e angariar novos votos - fez a audiência depararse consigo mesma, com o que mais deseja de si, com a sua condição mais 
gloriosa e bela. Todos voltados para a procissão dos vaqueiros, a atividade que abriu a celebração, contemplavam um modelo. O vaqueiro é uma imagem, embora em movimento, descarnada dos acontecimentos cotidianos. O couro que reveste a pele dos homens os libera dos juízos e das avaliações. Na parada, a despeito de quem são em suas vidas corriqueiras - até se são "vaqueiros, vaqueiros mesmo", como diz Pereira (2017: 22) -, quem os vê apenas testemunha não os sertanejos, mas o sertão inteiro, indiviso, em que o tempo, ao contrário dos animais, não se pode marcar.

Em I924, conforme me contou um de seus sobrinhos, João Gregório, na época do caso e do seu relato, grande tronco do povo da Ema, recebeu de Virgulino Ferreira, seu antigo vizinho, uma carta solicitando a retirada dele e de todos os parentes da ribeira por conta do parentesco que tinham com seus inimigos residentes na vila em cujo distrito a Ema encontra-se até hoje. Só seria permitida a visita periódica de um vaqueiro que, se encourado, não sofreria agressões e poderia olhar o gado livremente. A indumentária do vaqueiro é mais do que uma segunda natureza, é uma segunda pele que se solda às aspirações dos sertanejos todas as vezes em que ela é instada a atuar. Cada vez mais nas missas, portanto, antes do litúrgico e do festivo, ela é chamada a se manifestar num desfile. Porque sua imagem eterna, da bravura, do desassombro, do sofrimento e da humildade, ressoa na imagem que o sertão faz de si mesmo sob circunstâncias equivalentes. E é na missa do vaqueiro, na liturgia cristã, que essa figura conflui com o fundo que a inspira.

\section{A MISSA}

A missa de Totonho é uma homenagem a um vaqueiro, e a liturgia é entrecortada pelo ofertório dos couros: o peitoril, as luvas, as perneiras, o gibão, o chapéu, o cabeçal e o arreio. Após a Eucaristia com a hóstia consagrada, o mesmo gesto é repetido, mas com a distribuição de queijo coalho e rapadura, que ratifica a comunhão dos vaqueiros entre si. Ao Pai Nosso é acrescentado o Pai Nosso do Vaqueiro (como, de resto, ocorre em todas as missas do vaqueiro).

A missa em memória de Antonio da Costa Araújo é uma missa do vaqueiro como as que acontecem em todo o sertão, liturgia inaugurada pela missa do vaqueiro de Serrita em homenagem à morte de Raimundo Jacó, primo de Luiz Gonzaga, o "rei do baião", em consequência de uma intriga de famílias, quer dizer, uma sequência de vinganças de sangue cujo fundo é movido por laços de parentesco. A partir desse modelo, as missas do vaqueiro multiplicaram-se por muitos municípios e vilas sertanejas e seguem uma sequência que, ademais da estrutura brevemente descrita acima, são acompanhadas por toadas que homenageiam o modo de existência vaqueiro pela sua dureza, força, resiliência à dor e ao sofrimento e presentificam a memória de alguns dos vaqueiros mais ilustres da história sertaneja. ${ }^{9}$ As missas do vaqueiro são memoriais, no sentido estrito da palavra, sem os monumentos de pedra e cal: homenagens aos vaquei- 
ros que morreram. Assim como, de resto, veremos ao fim deste artigo, é o ritual da Igreja católica, um memorial ao mais importante de seus mortos em que a forma da morte como lhe foi dada tornou-se central, mas que não teria alguma importância não fosse o modo como conduziu a sua vida, até mesmo na preparação da sua morte. A missa para Totonho exigiu, vimos já, uma deriva da posição de Totonho à de vaqueiro. Napole o caracterizara como boiadeiro e vaqueiro, mas não dedicara a ele uma missa de vaqueiro.

E foi como vaqueiro, não como político, que Totonho, celebrado em seu local de morte e não de nascimento, tornou-se o tronco da família Ferraz da Ema. Nem como político nem como homem de armas; para fazer família os Ferraz da Ema recrutaram a imagem do vaqueiro - a figura mais relevante de toda a ecologia mental do sertão - e empregaram, como meio desse recrutamento, um homem cuja importância, salvo para a sua casa, era discreta, o nosso amigo Napoleão Ferraz Nogueira. A modéstia, a mansidão, o comunitarismo dos Ferraz da Ema exigiam uma figura como essa: catingueiro, discreto até o momento de descoberta de sua morte, mas de uma prole imensa, grandeza de alma e riqueza de espírito (a de moedas e rebanhos não foi enfatizada, salvo no breve texto de Napole, como vimos) tomadas de empréstimo de uma vida que não foi a sua. Vale repetir que essa não é obra do calculismo. Não há indícios de que, para Napole, idealizador da homenagem, o objetivo fosse criar um tronco novo para o povo da Ema. Nada no discurso e no planejamento que agora organiza o evento transparece o interesse em 'entrar na política'.

Uma descrição do ambiente da missa, muito mais do que a do ritual, poderá esclarecer melhor alguns desses aspectos. Nessa missa campal, uma grande tenda abrigava o altar e o que seria a nave da igreja, onde se dispunham as cadeiras de plástico para que os fiéis se sentassem. O lado de fora, descoberto, ao sol, era o lugar dos vaqueiros encourados escanchados em seus cavalos, distribuídos ao redor da tenda após seu desfile que fez parar toda a assistência. À sombra do arvoredo trabalhavam os políticos, candidatos ao pleito de outubro de 2016 , e os que pretendiam com eles negociar seus votos, alheios às homenagens que se iam prestar em seguida. Sob a tenda, em agitação, os e as responsáveis pela missa disputavam a atenção da audiência para dar início à cerimônia quando o conjunto musical começou a cantar as toadas em homenagem a Antonio da Costa Araújo.

Além dos versos já mencionados, a toada cantava seu cavalo selado chegando na casa da "família", que o procurou "pelo rastro do cavalo acharam debaixo de um pé de pereiro. O cachorro companheiro ali estava sentado". Sepultado ficou mesmo "na lagoa de Martin Mendes", onde "sempre será lembrado" aos 25 de agosto "a missa vamos celebrar, com bravura de vaqueiro, Totonho do Marmeleiro vamos homenagear". Enfim, após a marca de sua morte, o traço de sua vida: "todos os descendentes saibam que esse herói vaqueiro e a turma que homenageia tem sangue nas veias de Totonho do Marmeleiro". Outra toa- 
da conta que a celebração a Totonho "vem trazendo união" e sentir a emoção de "ter sangue de vaqueiro". "Antonio", segue a toada, é a "semente que nos traz e nos faz sentir mais família". "A missa firma um contrato entre todos os parentes, todo ano, mês de agosto, dê um jeito minha gente, último domingo do mês", é preciso "estar aqui novamente".

A esses cantos seguiu-se a liturgia propriamente dita. Às leituras de Lucas I4 e do Eclesiástico 3, que enfatizam a humildade, ${ }^{\text {Io }}$ seguiu-se a homilia, que enfatizou a modéstia de Totonho, emprestada de um dos traços do ofício de vaqueiro e do povo da Ema, e a grandeza que a determinava contrastando-as com a pequenez dos que desejam estar em primeiro plano, com os arrogantes e querelantes. Salvo nos bancos da igreja, dizia o padre, todos desejam sentarse à frente. Quando estão as autoridades, os políticos, todos desejam as primeiras filas. Ao redor, muitos dos ouvidos eram de mercador. Fora da tenda o único interesse eram os votos. Soubesse ou não o que se iria passar ali, a homilia acertou em cheio tanto da indireta aos candidatos quanto ao modo como o povo da Ema gostaria de se ver exposto publicamente e como se entende a si mesmo, conforme já mencionei.

A missa, portanto, é uma dupla homenagem: ao vaqueiro e à prole de Totonho. Em ambos os casos, esse é o único recurso de a ele emprestar uma vida que só é conhecida pela sua morte. Podemos notar que, ao contrário dos heróis, cuja morte aparenta-se aos atos de heroísmo, em certos casos físicos, em outros discursivos, no caso de Totonho, seja-me desculpada a iteração, é a morte apenas que o liga à vida de vaqueiro e à da sua descendência.

\section{OS VIVOS E SEUS MORTOS}

Tudo isso, é claro, dá a aparência do cálculo e da estratégia. Como no caso das leituras e da homilia, tática, improviso e alguma implausibilidade descrevem melhor como as coisas acontecem. Ao celebrar a primeira missa, Napole, decerto, não visava ampliar a capacidade eleitoral de algum parente, muito menos do lado dos Ferraz, uma vez que fora, durante toda a vida, seguidor dos Novaes da Fazenda Santa Paula e, daí, dos Ferraz do Nazaré (a vila que dista uma légua da Ema, célebre pelas lutas contra os irmãos Ferreira e depois contra o seu desdobramento, o cangaço de Lampião). Apesar de 'se assinar Ferraz', João Gregório não aderiu à política dos Ferraz. Napole queria celebrar um de seus mortos, retirá-lo do esquecimento e do isolamento na caatinga. Totonho não estava num cemitério, juntos aos seus, na proximidade dos que foram do seu sangue; seus restos deixados na caatinga não se reuniram, na morte, ao povo da Ema, em sua própria terra, no cemitério ali construído visando a esse fim. Sequer estava sepultado em seu sítio, como ocorre em certos casos. Esquecido na mente, esquecido em monumento.

Eis aqui um ponto central da thanasimologia. A memória-lembrança (para usar o conceito bergsoniano ${ }^{\mathrm{II}}$ ) é o lugar de contração de vivos, mortos, 
política e história. Entre minhas amigas e meus amigos de Floresta, para citar Marques (2013: 720), "as relações de parentesco sublinham todos os relatos do passado", sejam eles territoriais, oficiais, políticos ou das vinganças. Se lembram Weber, Langlois e Segnobos, já citados, a memória, a história jordanense também se formulam como as dos Wolof (Irvine, I978), e as dos Nuer (Evans-Pritchard, I978): elas falam das relações capazes de atualizar-se e reconhecer-se no tempo; mas fazem essa mnemotécnica genealógica fazer passado histórico. De modo que as e os genealogistas sertanejas(os) funcionam como agentes políticos que colaboram com os processos de composição e dissolução familiares.

Com toda razão, pode-se argumentar que não há especificidade nisso. E, de fato, essa é uma das principais contribuições que a thanasimologia sertaneja pode trazer às reflexões acerca do Estado, um dos objetivos, embora lateral, deste trabalho. Os Estados nacionais fazem-se empregando essa entre outras táticas de manutenção, como afirma Nora (I986), um dos maiores avalistas da religiosidade cívico-nacional francesa. Afinal, duas figuras se desprendem quando o Estado-nação é reclamado numa etnografia que descreve as relações entre memória, homenagens e família: a dos já mencionados heróis e a dos mártires. Totonho, tal como foi recuperado pelo povo da Ema, é próximo, mas irredutível a esses dois personagens.

Vejamos primeiro o caso dos mártires. Ikechukwu (2017), para um exemplo africano e, portanto, não distante de nós, mostra como no cristianismo os santos foram tratados como mortos-vivos sem os quais a Igreja não teria sobrevivido por tantos séculos, e para isso os martírios muito colaboraram e as relíquias dos mártires são ainda objetos centrais de culto e cobiça. A liturgia cristã, sobretudo a eucaristia, é destinada à lembrança de um morto, o mais relevante, o mais empregado ao longo da história. Segundo os evangelhos, esse é um ato feito por uma demanda do próprio homenageado: que se faça isso em minha memória. Totonho assemelha-se ainda aos mártires no aspecto da deriva da personagem dos mártires como indivíduos para o coletivo, conforme defendem Souza e Ciccarone (20 12), acerca das romarias do Mato Grosso, ainda mais próximo de nós. A Totonho, ao contrário, por conta de ser passível apenas de uma thanatografia, se lhe impõem o movimento contrário: o coletivo preenche todas as camadas do indivíduo, dá a ele uma biografia impossível de ser resgatada. Ele é humilde, modesto e cumpridor, tanto quanto os vaqueiros e o povo da Ema. Ademais, como bem lembra Albert (2007), o mártir define-se como alguém que entrega a vida, por consentimento, à morte certa para servir aos interesses da coletividade. Nenhum desses traços define a morte de Totonho, já que a vida é desconhecida, salvo por seus traços e pelo registro cartorial.

Os heróis congregam, fazem comunidade. Suas vidas, atos e palavras vulcanizam-se com certos objetivos de governo das pessoas e das coisas e são transliterados de modo a selecionar um conjunto de imagens e efetuar um feixe de relações de umas às outras. Vimos que Totonho funcionou para agregar, 
por meio do argumento do sangue, mais descendentes do que o tronco anterior do povo da Ema, João Gregório. Para um cenário em Nómeque, Andes colombianos, onde estão em vigor vinganças de sangue, Alvarez (200I) mostra a vingança associada ao culto do herói faccional, como ocorre no sertão de Pernambuco, ainda que a associação de política e família tenda a expandir essa condição às façanhas públicas municipais. Totonho, mais uma vez, não sendo herói, não se atém a uma família, mesmo que a homenagem seja construída a partir do modelo familiar-genealógico.

No sertão, não é a nação o valor mais universalmente legítimo da vida política, ao contrário da formulação excessivamente geral de Anderson (I99I. Ali, a família e o parentesco não são elementos de um conjunto metafórico e metonímico acionado pelo Estado-nação, como preferiu até recentemente uma certa antropologia do Estado (Anderson, I99i e, com outra abordagem e objetivos, Herzfeld, I985). Ela tampouco é um "lugar privilegiado para organizar a interface entre Estado e indivíduo", como bem sintetizou essa abordagem Sanjurjo (2013: 106).

O que torna os estudos da família, da política e dos mortos em Pernambuco relevantes para os debates concernentes a esses temas em antropologia é sua evidente rearticulação, uns em relação aos outros. No sertão de Pernambuco, a família lança mão de práticas e símbolos do Estado-nação para fazer-se. Ali, o Estado-nação é metáfora e metonímia. As famílias dispõem de heróis capazes de fundar linhagens políticas, de emprestar coragem e competência a descendentes por meio de seu sangue, seus enunciados e suas batalhas. Estes dedicam àqueles homenagens, canções e celebrações. Ainda nesse cenário singular, surgem outras singularidades, como essa de Totonho e do povo da Ema.

Amigos e amigas pertencentes a 'famílias antigas' no sertão de Pernambuco têm elaborado críticas à expressão pública do luto por meio das celebrações abertas e da exposição de banners com imagens dos mortos, uma das novidades nas relações dos mortos com os vivos. Uma democratização, digamos, da possibilidade de prestar homenagens públicas a mortos que não são públicos. 'E o sentimento?', duas das pessoas com quem conversei a esse respeito perguntaram. A ideia é a de que a dor interna que a falta do morto faz sofrer é substituída pela ostentação do amor. Defendi a ideia de que a relação com quem morreu precocemente era doméstica, própria ao ambiente da casa (Villela, 20I5). Essa crítica à deriva para o exterior na homenagem aos mortos confirma essa análise, mas diagnostica uma transformação no processo.

Esse tema é o mais geral da "veneração dos ancestrais", para usar a expressão do mesmo Ikechukwu (20I7: 39). No sertão, veneram-se os que se ligam a si, de modo que a recordação se reverta num fluxo mútuo de lembrança e prestígio. Isso se fez com personagens públicos, por conta de suas ações públicas, recordados em virtude de seu impacto público. Ao longo dessas quase duas décadas, eu só havia testemunhado esse esforço por meio da política propria- 
mente dita. Aqui se encontra a singularidade da celebração dos Ferraz da Ema. Um desvio não político, simultaneamente religioso (uma missa campal) e ligado à mais profunda e impactante tradição sertaneja, segundo os próprios sertanejos: o vaqueiro. Essas duas figuras inquestionáveis, circunstancialmente de alcance geral e inclusivas, permitem a adesão completa de não importa que família precisamente porque a produção não se dá em meio à disputa e à concorrência. A paz, a hospitalidade, formam, para os Ferraz da Ema - fazendo a transposição funcional e terminológica que o artigo propõe - o seu caráter nacional; o que os caracteriza como o povo da Ema: os descendentes do major João Gregório que carregam em seu sangue a benevolência, o pacifismo e a generosidade. Não está ao alcance de ninguém a antecipação dos possíveis engajamentos, proveitos e vantagens políticas que ela poderá, doravante, ensejar.

Este texto é inteiramente dedicado ao povo da Ema em geral, em especial às casas do Jericó e do Açude Novo que me entregaram ao longo desses anos o mais belo de todos os sertões.

Recebido em I9/3/2018 | Revisado em 22/3/2019 | Aprovado em Io/6/2019

Jorge Mattar Villela é antropólogo, professor-associado do Departamento de Ciências Sociais da UFSCar. Doutor em antropologia pelo PPGAS-Museu Nacional. É autor, entre outras publicações, dos livros $O$ povo em armas, Política e eleições no sertão de Pernambuco e Ordem pública e segurança individual. 


\section{NOTAS}

I Agradeço à Fapesp o financiamento do projeto "As Implicações das Vidas dos Mortos nas dos Vivos" (proc. oI6/03846-6), entre 2016 e 2018; as leituras e correções de Amelia Ferraz e Gilson Ferraz, organizadores da missa em Floresta; os comentários e sugestões das antropólogas Fernanda Peixoto, Ana Claudia Marques, Sara Munhoz, Dibe Ayube e Jacqueline Lima e do antropólogo Antonio Rafael Barbosa. Os equívocos, sabe-se, são todos meus.

2 Os termos em itálico pertencem à grade conceitual das e dos personagens desse artigo. Aspas simples são usadas para suas citações. Aspas duplas para citações de outras autoras e autores de publicações citadas na bibliografia.

3 Existe, é claro, a possibilidade de uma thanasimologia que se dirije à vida dos mortos como tais, mortos. A esse respeito, ver, por exemplo, Lima e Vander Velden (20I8).

4 O aspecto da campanha durante a missa será apenas mencionado quando necessário, pois sua descrição foge ao interesse deste artigo.

5 O verbo eleitoral acompanhar, mais do que o voto, envolve apoiar, gostar, se engajar.

6 Deputado geral no Segundo Reinado, deputado constituinte da República, duas vezes presidente da Câmara dos Deputados, eleito para o segundo mandato, para que se tenha alcance de seu prestígio, mesmo vivendo na Europa e, enfim, vice-presidente sob o mandato de Manoel de Campos Salles.

7 Embora situados na mesma microrregião de diversos municípios sertanejos, o Vale do Pajeú, triunfenses consideram-se brejeiros, pois uma parte do município localiza-se numa altitude de rooom. Seus terrenos em pequenos platôs formam uma estrutura fundiária muito diferente da sertaneja, assim como os cultivos e as criações de animais. Por este motivo, a ausência quase completa de caatinga e grandes propriedades fundiárias, não há e nunca houve vaqueiros ali.

8 Ana Claudia Marques em comunicação pessoal

9 São escassas as publicações sobre missas do vaqueiro: Lima (I99I) e Lima, Torres e Prazeres (2016). 
Io I4,I.7-I4: quem se elevar será humilhado; que se humilhar será elevado. "Jesus notou como os convidados escolhiam os primeiros lugares..."; Eclesiástico, 3: "Sê humilde e encontrarás a graça do Senhor". O tema da humildade, central para vaqueiros e para o povo da Ema, foi uma coincidência pois, sabe-se, as leituras diárias são escolhidas numa instância mundial da Igreja católica para todas as missas.

I I Uma memória hábito distingue-se em Bergson (I934: I64 e ss.), sabe-se bem, da "memória verdadeira" que "alinha nossos estados à medida que eles se fazem".

\section{REFERÊNCIAS BIBLIOGRÁFICAS}

Albert, Jean-Pierre. (2007). Martyre et mort volontaire en Europe. Bulletin of Death and Life Studies, 3.

Alvarez, Santiago. (200I). Enterrando heróis, patriarcas, suicidas e traidores. Mana, 7/2.

Anderson, Benedict. (I99I). Imagined community. London: Verso.

Bergson, Henri. (1934). Matière et mémoire. Essai sur la rélation du corps à l'esprit. Paris: Félix Alcan.

Cubitt, Geoffrey \& Warren, Allen. (2000). Heroic reputations and exemplary lives. Manchester: Manchester University Press.

Detienne, Marcel. (20I0). L’identité national, une enigme. Paris: Gallimard.

Evans-Pritchard, Edward. (I978) [1940]. Os Nuer. São Paulo: Perspectiva.

Ferraz, Gilson; Araújo, Maria Amelia \& Araújo, Magno. (20I5). Antonio da Costa Araújo (Totonho do Marmeleiro). Sua história e seus descendentes. Floresta: [s.n].

Hayden, Robert. (I996). Imagined communities and real victims: self-determination and ethnic cleansing in Yougoslavia. American Anthropologist, 23/4.

Herzfeld, Michael. (1985). The poetics of Manhood: contest and identity in a Cretan mountain village. Princeton: Princeton University Press. 
Ikechukwu, Nwafor. (20I7). The living-dead (ancestors) among the Igbo-African people: an interpretation of $\mathrm{Ca}$ tholic sainthood. International Journal of Sociology and Anthropology, 9/4.

Irvine, Judith. (1978). When is genealogy history? Wolof genealogies in comparative perspective. American Ethnologist, 5/4.

Jones, Max. (2007). What should historians do with heroes?. History Compass, 5/2.

King, Anthony. (20I0). The Afgan war and 'postmorten' memory. British Journal of Sociology, 6I/I.

Langlois, Charles-Victor \& Segnobos, Charles. (2014) [I897]. Introduction aux études historiques. Lyon: ENS.

Lima, Clarissa \& Vander Velden, Felipe. (2018). The dead among the living. In: Seebach, Sophie \& Willerlev, Rane. Mirrors of passing. Unlock the mysteries of death, materiality and time. New York: Berghahn.

Lima, Irenilda Souza; Torres, Adamastor Moreira \& Prazeres, Giselle Gomes. (20I6). Religião, cultura e desenvolvimento local: a missa do vaqueiro em Serrita - Pernambuco. Humanae, 10/2.

Lima, Jarniza. (I99I). Rezas ao sol: memória e tradição na missa do vaqueiro em Serrita-PE. Cadernos CERU, 3, p. 3348.

Marques, Ana Claudia. (2013). Founders, ancestors and enemies: memory, family, time and space in the Pernambuco Sertão. Journal of the Royal Anthropological Institute, I $9 / 4$.

Marques, Ana Claudia. (2003). Intrigas e questões. Rio de Janeiro: Relume Dumará.

Marschall, Sabine. (2008). Pointing to the dead: victims, martyrs and public memory in South Africa. South African Historical Journal, 60/1.

Nora, Pierre. (1986). Lieux de mémoire. La Nation. Paris: Gallimard.

Pereira, Renan. (20I7). Rastros e memórias: etnografia dos vaqueiros no Sertão (Floresta-PE). Dissertação de Mestrado. PPGAS/Universidade Federal de São Carlos. 
Petrovic-Steger, Maja. (20II). Anathomizing conflict. In: Lambert, Helen \& McDonald, Maarion (orgs.). Social bodies. Oxford: Berghan Books.

Rassool, Ciraj. (2004). The individual, auto-biography and history in South Africa. Tese de Doutorado. University of the Western Cape.

Sanjurjo, Liliana. (2013). Sangue, identidade e verdade: memórias sobre o passado ditatorial argentino. Tese de Doutorado. PPGAS/Universidade Estadual de Campinas.

Souza, Edmilson \& Ciccarone, Celeste. (20I2). Trânsito das almas: romarias camponesas e sacralização dos mártires da terra. Habitus, Io/I.

Verdery, Katherine. (1999). Political lives of dead bodies. New York: Columbia University Press.

Villela, Jorge Mattar. (2015). Os vivos, os mortos e a política no Sertão de Pernambuco. Revista de História, I73.

Villela, Jorge Mattar. (2009). Família como grupo? Política como agrupamento?. Revista de Antropologia, 52/I.

Villela, Jorge Mattar. (2004). O povo em armas. Violência e política no sertão de Pernambuco. Rio de Janeiro: Relume Dumará.

Villela, Jorge Mattar \& Marques, Ana Claudia. (2016). Le sang et la politique. Anthropologica, 58/2.

Weber, Max. (I968) [1904]. L'objectivité. De la connaissance dans les sciences et la politique sociales. In: Essais sur la théorie de la science. Paris: Plon.

Wilson, Luis. (I978). Roteiro de grandes e velhos sertanejos. 3 v. Recife: Cepe.

Wilson, Luis. (1974). Vila Bela, os Pereiras e outras histórias. Recife: Editora Universitária. 


\section{MEMÓRIA E THANASIMOLOGIA POLÍTICA NO SERTÃO DE PERNAMBUCO}

Resumo

Por meio da descrição analítica da constituição de um ancestral de uma extensa família, com base na celebração campal dedicada à memória de um vaqueiro falecido na década de 1850 no sertão de Pernambuco, mostro um dos modos pelos quais as famílias sertanejas fazem história de si mesmas. Alguns dos elementos dos seus métodos de fazer história, contada sob a forma da genealogia e legitimada pela existência de um fundador, costumam misturar-se à história política e administrativa do município em questão. Esse artigo mostra que as famílias, como os países, procuram fazer história com instrumentos como os monumentos, os personagens célebres que, no sertão -são chamados troncos, e a sua própria celebrização ritual.

\section{MEMORY AND POLITICAL THANASIMOLOGY IN THE PERNAMBUCO BACKLANDS, BRAZIL}

\section{Abstract}

Through the analytical description of the constitution of an ancestor of an extended family, based on the celebration of a mass dedicated to the memory of a man who died in the I 850 s in the Pernambuco backlands (sertão), I look to show one of the ways in which families in the region make their own history. Some of the elements of their methods of making history, told in the form of genealogies and legitimized by the existence of a founding father, frequently blend with the political and administrative history of the local municipality. Families, like countries, seek to make history using instruments such as monuments and celebrated figures - in the sertão called troncos, trunks - and their own ritual celebrations.
Palavras-chave

Mortos;

celebração; política; família; sertão.

\section{Keywords}

The dead; celebration; politics; family; sertão. 